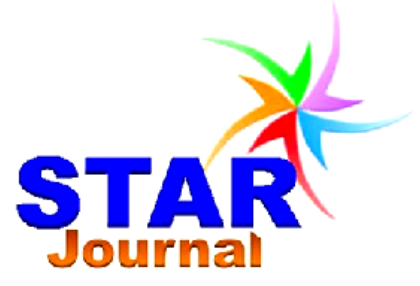

ISSN: 2226-7522(Print) and 2305-3327 (Online) Science, Technology and Arts Research Journal

\title{
Assessment of Sexual Behaviour, Attitude and Risk Perception about HIVIAIDS among Out-of School youths, Ilu-Abba-Bora Zone, Western Ethiopia
}

\author{
Elias Legesse Negeri
}

Faculty of Health Sciences, Post Box No: 395, Wollega University, Nekemte, Ethiopia

\begin{abstract}
To assess sexual behaviour, attitudes and risk perception about HIVIAIDS among out-of-school anti-AIDS club member and non-member youths in Mettu and Bedelle towns. The study applied a case control study design. The cases are club members those registered in the out-of-school anti-AIDS clubs and actively participated for at least one year. Controls are non-club member who have never been registered and never became active member of any anti-AIDS clubs anywhere in the towns. A pretested self administered questionnaire was used to collect data. Focus Group Discussions were also conducted in the two groups to complement the quantitative findings. From a total of 786 youths, 386 club members and 400 non-club members participated in the study. In this survey two third of the club members, $(66.6 \%)$ and one third of the non-club members $(33.2 \%)$ reported to have practiced sexual intercourse in the past. Among cases $31.3 \%$ reported that they had two and more than two sexual partners and $29.2 \%$ controls reported that they had more than two sexual partners. $45.9 \%$ of club members and $33.3 \%$ of non-club members had used condoms during the first time they had sexual intercourse. The majority $(99.1 \%)$ of the study populations were aware of HIVIAIDS. $72.5 \%$ of club member and $54.7 \%$ of non-club members perceived that they are at risk or may be at risk of acquiring the HIVIAIDS. The prevalence of multiple sexual partnerships over past year among both groups was $30.3 \%$ in the selected towns. The finding of the survey concluded both club member and non-club member out-of-school youths in this study area were exercising high risky sexual activities like early sex, multiple sexual partnerships, and inconsistent use of condom. But, the percentage among club members was lower than non-club members. Being a club member is protective for HIVIAIDS related risky Article Information Article History:

Received : 21-02-2012

Revised : 18-06-2012

Accepted : 21-06-2012

Keywords:

Sexual Risk Behaviours

HIVIAIDS

llu-Abba-Bora

Risk Perception

Out-Of School Youths

*Corresponding Author:

Elias Legesse Negeri

E-mail:

tsegishelias@yahoo.com sexual behaviors, perception.
\end{abstract}

\section{INTRODUCTION}

Globally, the HIVIAIDS epidemic remains a major public health, social, economic and development challenge. It poses significant threats in the world with impacts that will be felt for many decades in the future. In the most affected countries the pandemic is eroding decades of development gains, undermining economies, threatening security and destabilizing societies (UNAIDS, 2008; ILO, 2004).

Young adulthood is a stage in which human beings brought about many developments; (biological, physical, psychological, social) and these developments are accompanied by positive or negative behaviours depending on the environment in which the person grow. Sexual risk behaviours, including early sexual debut, unprotected sexual intercourse, and multiple sexual partners, occur in a broader context (Degaga, 2007; Youth Net, 2004).

Young people today are at high risk of unintended pregnancies and STIs, including HIVIAIDS, and those between 15 and 24 are both the most threatened and the greatest hopes for turning the spread of the HIVIAIDS epidemic 


\section{Elias Legesse Negeri}

since they are sexually active at younger ages than previous generations or delay in marriage until they are older, and do not use condoms regularly enough to ensure protection (Meseret, 2003).

The finding of this study is expected to contribute in filling the gap in understanding risky sexual practices related with the knowledge, attitudes and the risk perception of HIVIAIDS among youths in the study area. It is hoped that the out-come of this study will also shade some light as to the effectiveness of organizing antiAIDS clubs as one of the strategies of HIVIAIDS prevention and control programs and will be used by local or regional planners for further expansion and strengthening the method.

Therefore, this study will have an immense useful to the policy makers and program managers and those who are involved in reproductive health risk and sexual behaviour or any related issues in both towns.

\section{MATERIALS AND METHODS}

\section{Study Area and Period}

The study was conducted in Mettu and Bedelle towns which are located in llu-Abba-Bora zone, Oromia Regional state from January to June 2010G.C.

\section{Study Design}

The study applied a case control study design supplemented by qualitative studies (Focus Group Discussions and In-depth Interviews) The cases were club members those registered in the out-of-school anti-AIDS clubs and actively involved for at least one year. Controls were nonclub members who had never been registered and became active member of any anti-AIDS clubs anywhere in the two towns.

\section{Study Population}

The source populations for the study were all youths in the two towns, while the study populations were selected randomly from out-ofschool anti-AIDS club member and non-club member youths residing in Mettu and Bedelle towns.

\section{Sample Size}

The sample size for the quantitative survey was determined using a formula for comparison of two population proportions. $80 \%$ power and $5 \%$ type I error to approximate an acceptable population parameter was taken. Number of sexual partners, which is assumed to be the most
Sci. Technol. Arts Res. J., April-June 2012, 1(2):18-30

important risk factor in Ethiopia, was taken as a high risk behaviour indicator (Meseret, 2003).

The finding of a recent study carried out in Jimma and Agaro towns in the south west of Ethiopia was taken to represent the proportion. Out of sexually active respondents, $31 \%$ of club members and $17 \%$ of the non-club members reported to have had two or more life time sexual partners (Meseret, 2003). One control was taken for each case and $20 \%$ allowance for missing or non-response rate. Total sample size was 800 (400 cases (club members) and 400 for controls (non-club members)).

\section{Sampling Techniques}

For the club members, first list of youths who were active members for at least one year was prepared from the registration book of each town and kebele and used as a sampling frame. The members were listed in an ascending order. Following this a random numbers list of 400 youths were selected from both towns. The names of youths corresponding to the selected random numbers were included in the study. From all kebeles of the two towns, representative sample of control groups were selected.

The study subjects from 6 kebeles were recruited using systematic sampling which is proportionate to the number of households, which corresponds to the study unit. Every $k^{\text {th }}$ of the prenumbered households were selected and approached accordingly until the representative sample size was obtained. Interviewers of the quantitative survey have identified eligible discussants from the respective kebeles for the controls, and youth leaders for the club members or cases.

\section{Data Collection Procedure}

A quantitative data was collected using a questionnaire adapted from the BSS-Ethiopia 2001.The questionnaire was prepared originally in English and then was translated to Afan Oromo language. Pre-test of the questionnaire for clarity and consistency of the questions was conducted on some selected club member and non-club member youths of Gore and Algie towns (woredas from Ilu-Abba-Bora zone) one week prior to the actual data collection. Then, necessary amendment was made based on the feedback.

Two days training was given to data collectors and supervisors focusing on the objective of the study and value of collecting the actual data. For the club members, data collection was done at the respective youth centres in all kebeles in both 
Elias Legesse Negeri

towns, while house-to-house data collection was taken place for non-club members. Focus Group Discussions were made in quite class rooms and female youths Focus Group Discussions were moderated by female moderator while, that of males' group will be moderated by the principal investigator.

\section{Data Processing and Analysis}

Data obtained from the questionnaire was entered, cleaned and prepared for tabulation plan using statistical data analysis (using SPSS software version 17 and Epi info version 3.5 for windows) techniques. Frequencies for all variables were counted and cross tabulated by using percentage/proportions.

Uni-variate analysis was done for the selected variables. Then bi-variate analysis with crude odds ratio was used to test possible association of the independent variables with the dependent one. Furthermore, multivariate logistic regression analysis was used to see the net effects of each of the independent variables in explaining variation in the outcome variables. Proportions and percentages were calculated to show the distribution of the respondents by socioeconomic, demographic variables.

\section{Ethical Clearance}

This study was done in conformity with the ethical guidelines approved by the Institutional Review Board (IRB) of Addis Ababa University, Medical Faculty, Department of Community Health. Zonal Health Bureau and other concerned bodies were approached for collaboration and permission. Informed verbal consent was obtained from participants. Participants assured that privacy and confidentiality was maintained. At individual level after explaining the purpose of the study verbal and written consent was obtained from all participants prior to their participation in this study. They were also told to withdraw from the study at any time they want.

\section{RESULTS}

\section{Socio-Demographic Characteristics of the Study Participants}

A total of 786 youths participated in the study, with $100 \%$ response rate for non-club members and $96.5 \%$, response rate for the club members making 386 participants to which self administered questionnaire was administered.
Sci. Technol. Arts Res. J., April-June 2012, 1(2):18-30

Among the club member 164 (42.5\%) of the respondents were between the age range of 15 to 19 years, $222(57.5 \%)$ of them were between 20 to 24 years old and among the non-club member $186(46.5 \%)$ and $214(53.5 \%)$ of the respondents were between the age range of 15 to 19 years and between 20 to 24 years old respectively. The mean ages were $19.1 \pm 2.1$ and $18.2 \pm 2.2$ years for club members and for the nonclub members respectively.

Most of the club members, 300(77.7\%) were attending their education at different government and private institutions, $56(14.5 \%)$ do not have job and $30(7.7 \%)$ had job with average monthly income of 357 Ethiopian birr, of which $43.4 \%$ earning less than 200 birr per month, whereas from the non-club members $282(70.5 \%)$ were attending their education at different government and private institutions, $64(16 \%)$ do not have job and $54(13.5 \%)$ had job with the average monthly income of 420 birr. Most of the respondents among club member, 286(74.1\%) were living with their parents, while $100(25.9 \%)$ were living alone and from non-club member, 246(61.5\%) and $154(38.5 \%)$ were living with their parents and alone respectively.

Regarding the religion, greater than half of club members, 204(52.8\%) were Christian orthodox and followed by protestant, $142(36.8 \%)$, while the majority of non-club members, $218(54.5 \%)$ \& $154(38.5 \%)$ were Orthodox and protestant respectively. Most of respondents, 284(73.8\%) and $303(75.8 \%)$ of club members and non-club members were Oromo by ethnicity respectively.

\section{Sexual Experience of Survey Respondents}

This survey was found out that more than two third of the club members, $257(66.6 \%) \&$ about one third of the non-club members, $133(33.2 \%)$ claimed to have practiced sexual activity in the past; this result shows statistically significant proportion of out-of-school youths were sexually experienced in both groups $(P<0.05)$.

Age at first sexual intercourse varies by sex and age group among cases and controls. Among cases almost two third of who practiced sexual intercourse, 173(67.3\%) experienced the first sexual act in the age range of 15-19 years, while other age groups, $23.3 \%$ and $9.3 \%$ experienced the first sexual act in the age of less than 15 years and in the age range of 20-24years respectively. In the controls, more than half of those who practiced sexual intercourse, $76(57.1 \%)$ experienced the first sexual acts in the age range $15-19$ years, and $30.8 \%$ and $14.2 \%$ experienced the first sexual act in the age range 
Elias Legesse Negeri

less than 15 years and in the age range of $20-24$ respectively.

Having had sexual intercourse for both sexes rises with age from $32(18.2 \%)$ in the age group less than 15 years to $128(72.7 \%)$ in the age group 15-19 years among club members, whereas among non-club member youths having had sexual intercourse for both sexes also rises with age from $26(29.9 \%)$ in the age group less than 15 years to $51(58.6 \%)$ in the age group of 15-19 years.

The study result indicated that, the minimum and maximum age of sexual initiation for males was 12 and 22 years and for females was 10 and 18 years respectively. Amongst cases the mean age of sexual initiation for males and females was $16.9( \pm 1.8)$ and $16.6( \pm 2.2)$ years respectively. The mean age of sexual debut among controls for males and females was $17.3( \pm 1.9)$ and $15.1( \pm 2.6)$ respectively. This shows that females had more likely started sexual activity earlier than males in both groups which was statistically significant $(P<0.05)$.

Out of $257(66.5 \%)$ club member respondents who had sex, 195(75.8\%) of them had sexual intercourse during the previous 12 months. Among these, $68.6 \%$ and $31.4 \%$ were males and females respectively. While, out of $133(33.3 \%)$ non-club member respondents who had sex, $77(57.8 \%)$ of them had sexual intercourse during the previous 12 months. Among these, $55.8 \%$ and $44.2 \%$ were males and females respectively. More number of male, $68.8 \%$ than female, $31.2 \%$ youths among the club members were engaged in sexual activity in the last 12 months. The same difference was also observed among male and female of non-club member youths.

The majority $265(68.7 \%)$ of the club members reported that they had one sexual partner and of which, $182(68.7 \%)$ and $83(31.3 \%)$ were males and females respectively. The remaining $121(31.3 \%)$ respondents reported that they had two and more than two sexual partners and of which, $82(67.7 \%)$ and $39(32.3 \%)$ males and females respectively. Besides this, $283(70.8 \%)$ of non-club members reported that they had one sexual partner and of which 194(68.6\%) and $89(31.4 \%)$ were males and females respectively. The remaining $117(29.2 \%)$ respondents reported that they had greater than two sexual partners and of which $88(75.2 \%)$ and $29(24.8 \%)$ males and females respectively.

This study revealed that the relationship between age and number of lifetime sexual
Sci. Technol. Arts Res. J., April-June 2012, 1(2):18-30

partners, so the trend of having two and more than two sexual partners shows an increment as youth's age level increase. That is among 15-19 age group (44.5\%) have more than one life time sexual partner whereas, among 20-24 age groups are $(55.4 \%)$ in both groups. From this, we can observe that males had more likely high number of sexual partners than their female counter parts.

Among club members sexually initiated males reported to have an average of 2.5 life time partners, whereas females reported 1.9 life time partners. From non-club members sexually active males said that an average of 2.1 life time partners, while females reported that 1.5 life time partner. With respect to the number of sexual partners they had in the last 12 months, higher proportion $(25.9 \%)$ of the sexually active club members had more than one partners as compared to that of non-club members $(12.8 \%)$.

About $35(9.8 \%)$ and $22(5.5 \%)$ of the sexually active club member and non-club member adolescents reported history of signs and /or symptoms of STIs. The proportion of reported STIs was higher in males (19.5\%) than in females (13.1\%) among club members.

\section{Unprotected Sexual Practice}

Amongst 257(66.5\%) club members who ever had sex, $118(45.9 \%)$ had used condoms during the first time they had sexual intercourse and of which, $72(56.7 \%)$ and $46(40.9 \%)$ were males and females respectively. Out of $133(33.3 \%)$ nonclub members who ever had sex, $46(34.5 \%)$ had used condoms during the first time they had sexual intercourse and of which, 27(41.3\%) and $19(31.0 \%)$ were males and females respectively.

Among 195(75.8\%) club member youths who were sexually active in the previous 12 months, $138(70.7 \%)$ youths of which, $94(68.1 \%)$ males and $44(31.9 \%)$ females reported condom use during their most recent sexual encounter. From $(55.1 \%)$ of respondents of which, $63.1 \%$ males and $36.9 \%$ said that condom use was suggested by joint decision. Thirty point four percent $(61.9 \%$ males \& $38.1 \%$ females) and $14.5 \%$ (60\% males and $40 \%$ females) reported that it was suggested by themselves and their partner respectively.

However, $57(29.3 \%)$ club members of which, $37(64.9 \%)$ males and $20(35.1 \%)$ females reported that they had not used condoms in their most sexual encounter. The commonest reasons for non-use of condoms reported were partner trust $(54 \%)$ and do not enjoy sex when using condoms (it decreases sexual pleasure) $(26 \%)$. 
When we compare the two groups as to the types of partners with whom they practiced sex revealed that, more proportion $(7.5 \%)$ of non-club members had visited commercial sex workers than club members $(2.7 \%)$. While, none of seven club members admitted to have sexual contact with commercial partners without condom, but three of the ten $(30 \%)$ non-club members having sexual contact with commercial sex workers without using condoms.

\section{Knowledge, Attitude and Stigma about HIVIAIDS and Other STIs}

The majority $(99.1 \%)$ of both groups of the study populations were aware of HIVIAIDS. The proportion of those who have ever heard about the HIVIAIDS epidemic is higher in club members $386(100 \%)$ than in non-club members $393(98.2 \%)$ youths.

About $95.2 \%$ of non-club members and $99.5 \%$ club members correctly identified unprotected sexual intercourse as mode of transmission for HIV, but only $51 \%$ of non-club members and $74.3 \%$ of club members correctly identified MTCT as mode of transmission for HIV. More than $80.3 \%$ of club members and $75.7 \%$ non-club members correctly identified contaminated blades and sharp materials as mode of transmission for HIV. Mosquito bite was misconceived and mentioned as a risk factor of HIV infection by $8 \%$ of non-club member and $4.7 \%$ of club member respondents.

Blood transfusions, 306(79.2\%); breast feeding of infected mothers, 128(33.1\%); deep kissing, 24(6.2\%); unsafe injection, 295(76.4\%) were the most commonly mentioned modes of transmission by the club members. While, blood transfusions, 298(74.5\%); unsafe injection, 264(66.0\%); breast feeding of infected mothers, $142(35.5 \%)$; followed by deep kissing, 41(10.2\%); were the once most frequently replied responses by the non-club members.

As far as STIs are concerned, $96.6 \%$ and $92 \%$ of club member and non-club member respondents were familiar with at least one type of STIs other than HIVIAIDS respectively. Gonorrhoea $(79.7 \%)$; syphilis $(75.3 \%)$ and cancroid $(57.5 \%)$ were the commonly stated STIs among club member youths. In the case of nonclub members gonorrhoea $(74 \%)$; syphilis $(75.5 \%)$ and cancroid $(61 \%)$ were the usually known STIs. $77.8 \%$ and $88.3 \%$ of the respondents did not know the LGV from club members and non-members respectively.

\section{Contraceptive Use}

More than half $(52.5 \%)$ of club members and $(26 \%)$ non-members reported that they used the contraceptive methods during their last sexual intercourse respectively. Among the club members the types of contraceptives used were condom $(72.5 \%)$, pills $(42.5 \%)$ and calendar $(5.7 \%)$ methods. While, the types of contraceptives used by non-club members were condom, pills and calendar, $20 \%, 16.2 \%$ and $7.5 \%$ respectively. The major reasons for using contraceptive methods for club members and non-members as they reported were to prevent unintended pregnancy $118(58.1 \%)$ and $46(44.2 \%)$, while others said that to prevent HIVIAIDS and other STIS 79(38.9\%) and $50(48.1 \%)$ respectively.

The data shows that more females (54.5\%) than males $(51.5 \%)$ used the contraceptive methods during their last sexual intercourse among club members. The same thing was happened in the non-club members except the percentage difference i.e. (30.5\%) and (24.1\%) of females and males respectively.

\section{Attitudes towards Risks of Sexual Activities and HIVIAIDS among Youths}

About $243(62.9 \%)$ and $187(46.7 \%)$ of the participants perceive that a person could get HIV the first time he/she had sex amongst club members and non-members. The odds ratio result points out that non-club members do not have good attitude towards PLWHA than club member youths $(\mathrm{AOR}=1.38(1.39,2.54))$.

In addition, club members are more or less agree with the opinion that a boy/girl should have sex before he/she gets married as non-club members $(A O R=1.29,(0.95,1.90))$. With regard to AIDS patients' treatment and care, almost all of both groups had affirmative feelings even if the proportion of club members still outweighs the non-club members.

\section{Risk Perception}

Participants' attitude towards perceiving themselves as susceptible to HIV infection was asked and the result indicated that, 112(29\%) respondents replied that they had no chance of acquiring HIV, 187(48.4\%) claimed to have low, $58(15.1 \%)$ medium and $29(7.5 \%)$ high chance of acquiring the virus.

Almost three fourth, $280(72.5 \%)$ of club members perceived that they are at risk or may be at risk of acquiring the disease than the nonclub members $219(54.7 \%)$. The differences are 
Elias Legesse Negeri

statistically significant $\quad(\mathrm{AOR}=3.32, \quad(1.28$, 7.29)). The most frequently mentioned reason by youths who did not perceive themselves as at risk of acquiring HIV were, 106(27.5\%) that they did not have any sexual contact; $14(13.2 \%)$ were that they regularly use condom and 22(20.8\%) because of praying regularly. The proportions that perceive themselves at risk of contracting HIV are highest among females, 345(69.1\%) than males, 154(30.9\%).

A number of factors including the number of lifetime sexual partners, knowledge on HIV transmission, willingness to get tested (VCT), condom use during first sexual intercourse and alcohol intake have shown significant association with self-risk perception.

Youths who were reported to have two or more sexual partners perceived themselves as at high risk of getting HIV than those with single sexual partner $(A O R=2.79(1.24,4.43)$. Risk perception of HIV significantly increases with the number of sexual partners. Those who have knowledge on HIV transmission feel that they are at high risk than those who were not knowledgeable $(A O R=2.93,(1.45,4.35)$. Those who use condom perceive that they are at lower risk of HIV than those who didn't use condom $(A O R=2.3(0.14$, 0.67 ) and youths who drank alcohol feel that they are at higher risk than those who were not $(\mathrm{AOR}=0.99,(1.54,1.86))$.

\section{Having Ever Had Sex among the Respondents with Different Variables}

Age of the respondents showed statistically significant association with their sexual behavior. Accordingly, the odds of having had sexual intercourse among youths in the age group 15-19 were 1.96 times higher than in the age group 2024 years, $(A O R=1.96(1.21,3.04))$.

Living arrangement of youths' appears to have statistically significant relationship with their sexual behavior $(\mathrm{AOR}=2.75(1.26,4.74))$. This survey result revealed that, youths those currently living alone were 2.75 times more likely sexually experienced than youths who were currently living with both parents.

Parent-youths communication on sexual matter was another important variable to influence youths' sexual experience. In this study, youths who reported to have had the chance of discussion with their parents had low engagement to sexual practice than their counter parts, $(A O R=1.53(1.29,3.96))$.
Sci. Technol. Arts Res. J., April-June 2012, 1(2):18-30

Alcohol drinking and watching pornographic films are also found to be significant with their involvement in sexual practice. The data revealed that youths who ever drunk alcohol were 1.41 times more likely to have had $\operatorname{sex}(A O R=1.41(0.24,0.61))$ and youths those watching pornographic films were 1.87 times more likely ever had sex than their counterparts. $(\mathrm{AOR}=1.87(1.53,3.25))$

\section{Number of Lifetime Sexual Partners of the Respondents with Different Variables}

Based on the study result, age groups, average monthly income of respondents and chat chewing shows a significant association with the number of life time sexual partners.

The odds of having multiple sexual partners among adolescents who have had an income more than 500 birr is 1.63 times more likely to have multiple sexual partners than the opposite groups $(\mathrm{AOR}=1.63(0.92,3.41))$.

This study revealed that, as the age of the youth's increase the probability of the youths to have more than one life time sexual partners' increases. Among sexually active respondents $30.3 \%$ and $30.2 \%$ of $15-19$ and $20-24$ age groups respectively, have had multiple sexual partners before the study.

The odds of having multiple sexual partners among youths who were chewing khat is 1.52 times more likely to have multiple sexual partners than their counter parts. $(A O R=1.52(0.23,0.93))$.

\section{Consistence Use of Condom in the Last 12 Months with Selected Background Characteristics}

This study result revealed that variables like sex, age categories; the number of lifetime sexual partners and educational levels shows a significant association with the pattern of condom use in the last 12 months.

Those with secondary educational level, (AOR= $2.33(1.82,6.24))$ and those who reported to have single sexual partner, $(A O R=2.34(1.27,5.68))$ use condom less frequently than those who had elementary education and those who had two or more sex partners, respectively.

Respondent's sex was one of important predictors, which has influence on consistence use of condom in the last 12 months. The odds ratios for female respondents were found to be 2.65. That is the likelihood of not using condoms consistently among female students in the last 12 
Table 1: Comparison of selected variables and own risk perception among youths in Mettu and Bedelle towns, 2010.

\begin{tabular}{|c|c|c|c|c|c|}
\hline \multirow{2}{*}{\multicolumn{2}{|c|}{ Characteristics }} & \multicolumn{2}{|c|}{ Risk perception } & \multicolumn{2}{|c|}{ OR $(95 \% \mathrm{Cl})$} \\
\hline & & Yes & No & Crude & Adjusted \\
\hline \multirow{2}{*}{ Study group } & Club member & 280 & 106 & $2.60(1.13,6.12)$ & $3.32(1.28,7.29)^{\star \star}$ \\
\hline & Non-club member & 219 & 181 & 1.00 & 1.00 \\
\hline \multirow{2}{*}{ Sex } & Male & 155 & 199 & $0.79(0.57,2.43)$ & $1.11(0.49,2.03)$ \\
\hline & Female & 345 & 88 & 1.00 & 1.00 \\
\hline \multirow{2}{*}{ Age group } & $15-19$ & 220 & 129 & $1.64(1.17,2.34)$ & $0.82(0.38,1.79)$ \\
\hline & $20-24$ & 279 & 158 & 1.00 & 1.00 \\
\hline \multirow{3}{*}{$\begin{array}{l}\text { Educational } \\
\text { status }\end{array}$} & Elementary & 30 & 19 & 1.00 & 1.00 \\
\hline & Secondary & 83 & 43 & $1.24(0.16,9.33)$ & $0.67(0.10,4.52)$ \\
\hline & College and above & 386 & 225 & $3.86(2.86,6.45)$ & $5.72(1.93,5.17)$ \\
\hline \multirow{2}{*}{ Marital status } & Never married & 436 & 242 & 1.00 & 1.00 \\
\hline & Married & 63 & 45 & $1.44(0.88,2.36)$ & $0.90(0.44,1.86)$ \\
\hline \multirow{2}{*}{$\begin{array}{c}\text { Knowledge of } \\
\text { HIV } \\
\text { prevention }\end{array}$} & Knowledgeable & 439 & 242 & $1.3(1.06,2.22)$ & $2.93(1.45,4.35)^{\star *}$ \\
\hline & Not knowledgeable & 60 & 45 & 1.00 & 1.00 \\
\hline \multirow{2}{*}{$\begin{array}{l}\text { No of life time } \\
\text { sexual partner }\end{array}$} & $>$ two & 153 & 87 & $0.93(0.89,3.54)$ & $2.79(1.24,4.43)^{\star \star}$ \\
\hline & One & 346 & 200 & 1.00 & 1.00 \\
\hline \multirow{2}{*}{$\begin{array}{l}\text { Condom use } \\
\text { during first } \\
\text { sexual } \\
\text { intercourse }\end{array}$} & Yes & 204 & 110 & $1.12(0.36,1.22)$ & $2.30(0.14,0.67)^{\star *}$ \\
\hline & No & 295 & 177 & 1.00 & 1.00 \\
\hline \multirow{2}{*}{$\begin{array}{l}\text { Willingness to } \\
\text { get VCT }\end{array}$} & Yes & 322 & 173 & $0.85(0.50,1.43)$ & $0.67(0.30,1.49)$ \\
\hline & No & 177 & 114 & 1.00 & 1.00 \\
\hline \multirow{2}{*}{ Drink alcohol } & Yes & 277 & 163 & $0.95(0.57,1.98)$ & $0.99(1.54,1.86)^{\star \star}$ \\
\hline & No & 222 & 124 & 1.00 & 1.00 \\
\hline \multirow{2}{*}{ Khat chewing } & Yes & 302 & 175 & $1.80(0.70,5.94)$ & $1.39(0.30,4.28)$ \\
\hline & No & 197 & 112 & 1.00 & 1.00 \\
\hline
\end{tabular}

months is 2.65 times more likely that of male students.

The estimates of the age suggest variation in the odds of consistent use of condom in the last 12 months during sexual intercourse for the age group of $15-19$ and $20-24$. The odds ratios of condom use in the last 12 months who have age 15-19 were found to be 1.78 . This means that respondents in the age group 15-19, 1.78 times less likely used condom consistently in the last 12 months during sexual intercourse than the reference category (20-24). 
Table 2: Relationship between selected socio-demographic variables and sexual behaviour of out-ofschool youths, Mettu and Bedelle towns, 2010.

\begin{tabular}{|c|c|c|c|c|c|}
\hline \multirow{2}{*}{\multicolumn{2}{|c|}{ Characteristics }} & \multicolumn{2}{|c|}{ Ever had sex } & \multicolumn{2}{|c|}{ OR $(95 \% \mathrm{Cl})$} \\
\hline & & Yes & No & Crude & Adjusted \\
\hline \multirow{2}{*}{ Study group } & Club member & 257 & 129 & $3.99(0.81,2.47)$ & $1.96(0.293,1.21)$ \\
\hline & Non-club member & 133 & 267 & 1.00 & 1.00 \\
\hline \multirow{2}{*}{ Sex } & Male & 263 & 283 & $0.82(1.01,1.99)$ & $1.45(0.84,3.88)$ \\
\hline & Female & 127 & 113 & 1.00 & 1.00 \\
\hline \multirow{2}{*}{ Age group } & $15-19$ & 251 & 244 & $1.12(0.88,2.51)$ & $1.96(1.21,3.04)^{* *}$ \\
\hline & $20-24$ & 139 & 152 & 1.00 & 1.00 \\
\hline \multirow{3}{*}{$\begin{array}{l}\text { Educational } \\
\text { status }\end{array}$} & Elementary & 35 & 27 & 1.00 & 1.00 \\
\hline & Secondary & 138 & 138 & $0.77(0.17,1.43)$ & $0.95(0.23,0.96)$ \\
\hline & College \&above & 217 & 231 & $0.72(0.19,3.64)$ & $1.72(0.52,2.54)$ \\
\hline \multirow{3}{*}{$\begin{array}{l}\text { Family } \\
\text { economic } \\
\text { status }\end{array}$} & Rich & 61 & 55 & 1.00 & 1.00 \\
\hline & Medium & 255 & 258 & $0.89(0.43,1.37)$ & $1.48(0.43,2.52)$ \\
\hline & Poor & 74 & 83 & $0.81(0.48,2.63)$ & $1.77(0.32,3.23)$ \\
\hline \multirow{2}{*}{$\begin{array}{c}\text { Parent } \\
\text { youths } \\
\text { discussion } \\
\text { about sexual } \\
\text { matters }\end{array}$} & Yes & 260 & 246 & $1.21(1.08,3.31)$ & $1.53(1.29,3.96)$ ** \\
\hline & No & 130 & 150 & 1.00 & 1.00 \\
\hline \multirow{2}{*}{ Religiosity } & Regularly attending & 334 & 343 & $0.92(2.60,3.52)$ & $1.66(0.93,3.31)$ \\
\hline & Never attend & 56 & 53 & 1.00 & 1.00 \\
\hline \multirow{2}{*}{$\begin{array}{l}\text { Alcohol } \\
\text { consumption }\end{array}$} & Yes & 214 & 222 & $1.95(0.44,2.42)$ & $1.41(0.24,0.61)^{* *}$ \\
\hline & No & 176 & 174 & 1.00 & 1.00 \\
\hline \multirow{2}{*}{$\begin{array}{l}\text { Pornographic } \\
\text { films }\end{array}$} & Yes & 235 & 243 & $1.06(0.54,2.56)$ & $1.87(1.53,3.25)^{* *}$ \\
\hline & No & 155 & 153 & 1.00 & 1.00 \\
\hline
\end{tabular}

\section{DISCUSSION}

The results of the survey indicates that, more than two third of the club members, $66.6 \%$ (58.1\% males, $31.5 \%$ females) and about one third of the non-club members, $33.2 \%(65.4 \%$ males and $34.6 \%$ females) claimed to have practiced sexual intercourse in the past.

The results of similar studies conducted among out-of-school adolescents in Ethiopia showed that, in Addis Ababa $52 \%$ for males and $47.8 \%$ for girls (Kidanu et al., 2002); in Bahir Dar 53\% for males and $24 \%$ for females (Abate, 2001), in southern Ethiopia $49 \%$ for both sexes (Wosen, 2005 ), in Gondar the figure ranged from $42 \%$ to $56.1 \%$ for both sexes claimed to have practiced sexual intercourse in the past (Silieshi, 2005). In this survey the figure is relatively higher when compared to these studies, and shows there is high engagement in sexual intercourse which may be due to being out-of-school stimulates sexual activity, and the risk taking behavior concerning premarital sex may increase among the out-of-school youths.

This study identified that, amongst cases the mean age of first sexual inter course for males and females was $16.9 \pm 1.8$ and $16.6 \pm 2.2$ years respectively. The mean age of first sexual intercourse among controls for males and females was $17.3 \pm 1.9$ and $15.1 \pm 2.6$ respectively. This study had also revealed females began sex earlier than males. From the total of the study 


\section{Elias Legesse Negeri}

subjects the minimum and maximum age of sexual initiation for males was 12 and 22 years and for females 10 and 18 years respectively.

Similar study conducted in Jimma and Agaro towns identified the mean age of first sexual practice was $16.8 \pm 1.9$ and $16.8 \pm 2.1$ years respectively for the two study groups. The minimum age reported was 10 years for both sites. In this study the mean age of first sexual intercourse is almost similar with a study conducted in Jimma and Agaro towns and in eastern part of Ethiopia.

Age at first sexual intercourse varies by sex and age group among cases and controls. In the cases almost two third of who practiced sexual intercourse, $(67.3 \%)$ experienced the first sexual intercourse in the age range of 15-19years, while $(23.3 \%)$ and $(9.3 \%)$ experienced the first sexual act in the age range less than 15years and 2024years respectively. In the controls, more than half of those who practiced sexual intercourse, $(57.1 \%)$ experienced the first sexual acts in the age range of $15-19$ years, whereas $(30.8 \%)$ and $(14.2 \%)$ experienced the first sexual act in the age range less than 15 years and 20-24 respectively. Similar study conducted in Bishoftu town reported that, youths in the age group 20-24 years old were 1.987 times more likely to have had sexual intercourse compared with youths in the age group of 15-19 years old.

The result of this study also indicates that sexual experience increase with age and the age of the respondent has a profound effect on sexual behavior of the youths. This association between age and sexual initiation coincides with the usual trend that the higher the age, the higher the risk of being sexually experienced. The reason reported in FGD is that, as age increases parental control decreases, and then they are exposed to sex films, substances like alcohol and chat, which leads them to experience risky sexual behaviors. In the present study most of the youths experienced the first sexual activity between ages of 15-19.

This study explain that there were different reasons for starting of sexual intercourse like having had personal desire, peer pressure, fall in love and to maintain relationship with partner were the most common reasons to start the first sexual intercourse among cases and reported by $40.9 \%, 32.9 \%, 31.8 \%$ and $21.1 \%$ respondents respectively. While, having had personal desire, peer pressure, fall in love and to maintain relationship with partner were the most common reasons to start the first sexual intercourse
Sci. Technol. Arts Res. J., April-June 2012, 1(2):18-30

among controls and reported by $39.8 \%, 22.5 \%$, $22.5 \%$ and $15.2 \%$ respondents respectively.

This trend is consistent with the study conducted in Nekemte and Addis Ababa high school students; and found out that adolescents engaged in the practice of sexual intercourse for the first time due to love affairs, having had personal desire, peer pressure, to maintain relationship with partner and by force (Eggleston, 2000; Hibret, 2004). A study conducted in Jamaica also revealed that motives and reasons for engaging in sexual intercourse were curiosity and love, gift obtained from friends and being forced into it (Ahimbisibwe et al., 2000).

In the present study, regarding the number of lifetime sexual partners, respondents who are sexually active $(31.3 \%, 29.2 \%$ among cases and controls respectively) have ever had two or more sexual partners and this agrees with the other studies conducted elsewhere in the country.

In terms of age, the trend of having two and more sexual partners show an increment as youth's age level increase i.e. among 15-19 age group (44.5\%) and among $20-24$ age groups $(55.4 \%)$ have more than one life time sexual partner $(A O R=1.72(1.42,2.79))$. In the present study, sexually initiated males and females reported an average of 2.5 and 1.9 life time partners from the club members respectively. From non-club members sexually active males and females reported to have an average of 2.1 and 1.5 life time partners.

FGD result substantiates that, it is usual among the youths to have sexual intercourse with more than one sexual partner. In this study, males had more likely high number of sexual partners than their female counter parts, but there was no statistically significant difference between the twogroups. The mean number of lifetime sexual partners among cases and controls were relatively higher than the aforementioned study conducted in Jimma and Agaro towns.

In this survey, out of $(66.5 \%)$ club members who ever had sex, $(45.9 \%)$ had used condoms during the first time they had sexual intercourse. Out of $(33.3 \%)$ non-club members who ever had sex, $(34.5 \%)$ had used condoms during the first time they had sexual intercourse.

The reported low utilization rate of condom in this study area may indicate that high-risk behaviors are widely practiced in the area. This calls for a well organized information, education and communication through peer educators to 


\section{Elias Legesse Negeri}

bring about behavioral change. Although, there was low utilization of condom in these study areas condom use is significantly increased in two fold among cases than controls.

In Ethiopia, EDHS 2006 indicated that condom use among adolescents is low, only (1\%) of young women and $(17 \%)$ of young men used condom during their first sexual intercourse. Condoms remain the integral part of HIV prevention programs. However; the prevalence of condom use is low despite all efforts made to improve the use of it (Melisew, 2008).

This study revealed that, out of $(75.8 \%)$ club members who have had sex during the previous 12 months, $(58.3 \%)$ reported that they were using condoms every time. Thirty three point four percent $(33.4 \%)$ reported that they were using condoms some times and (12.8\%) reported that they had never used condoms during sex in the past 12 months.

From $(57.8 \%)$ non-club members who have had sex during the previous 12 months, (55.8\%) reported that they were using condoms every time, $31.1 \%$ reported that they were using condoms some times and (12.9\%) reported that they had never used condoms during sex in the past 12 months.

In a study conducted in Jimma and Agaro towns, south west Ethiopia, among sexually active respondents during the last one year, $(46 \%)$ of the club members and $(39.3 \%)$ of the non-club members reported to use condom every time and more males reported to use condom compared to the female youths (Meseret, 2003).

In other study conducted in Uganda, older youths (20-24 years) reported to use condom more than the younger once (15-19 years) (Hibret, 2004). In a study conducted in Bahir Dar town, $(37.3 \%)$ and $(36.8 \%)$ of out-of-school youths reported that they used condom every time when they have sexual intercourse with commercial sex partners and with non-regular sexual partners respectively (Lema and Hassen, 1994). The result obtained from this study was much higher than that of Jimma, Agaro and Bahir Dar towns and more males reported to use condom compared to the female youths.

FGD result also showed that, females are less likely to use condom. This may be due to cultural and other reasons such as the decision power and asking her sexual partner to use condom. In the same way, this study also confirms that older
Sci. Technol. Arts Res. J., April-June 2012, 1(2):18-30

youths (20-24 years) reported to use condom more than the younger once (15-19 years).

The proportion of club member youths who had unprotected sexual intercourse at least once were higher than those non-club member counter parts $(46.1 \%$ Versus $44.1 \%)$ and this was statistically significant $(P<0.05)$. From this, we can observe that many youths had been engaged in a risky sexual behaviour that could make them vulnerable to STIs including HIVIAIDS, unwanted pregnancy, abortion, termination from school.

A study conducted in Injibara town, Awi zone, revealed that $(22.6 \%)$ of young people used condom during their first sexual encounter and $(77.4 \%)$ of young people did not use condom during their first sexual encounter. In addition, the proportion of condom users at the first sex were considerably higher among males than females (67\% versus $33 \%$ ) (Silieshi, 2005).

Young people in the study areas protect themselves from HIVIAIDS, other STIs and unwanted pregnancy. But, the required level of using condom was not reached yet. The proportion of condom users at the first sex was considerably higher among males than females (41.3\% versus $31 \%)$. Higher educational attainment, greater wealth, and urban residence are related to a greater likelihood that condoms were used at the first time (Silieshi, 2005).

A recent survey in Afar region reported that consistent condom use during experiencing sex with commercial sex workers among out-ofschool youths were $(58 \%)$ and $(36 \%)$ reported experiencing commercial sex using condom occasionally and none of them reported consistent condom use (Abate, 2001).

In this study, when we compare the two groups as to the types of partners with whom they practiced sex revealed that, though statistically not significant, more proportion $(7.5 \%)$ of nonclub members had visited commercial sex workers than club members $(2.7 \%)$.

The alarming finding of this study is that, a significant percentage $(28.5 \%)$ club members admitted to have sexual contact with commercial partners without using protective measure (condom), (30\%) non-club members having similar contact and didn't use condom consistently.

From FGD, no condom dispensary is found in the study areas. Many kiosks carry condoms, but youths are reluctant to purchase them in their 
Elias Legesse Negeri

own neighborhoods' for fear of being labeled promiscuous.

The present findings indicates that majority of out-of-school youths were at increased risk of HIVIAIDS, because they were neither using condom consistently nor abstain from sex and this figure was much less than a study conducted in Afar region which indicates that there is a better usage of condom in the present study areas.

Result from the study indicated that, almost the majority $(99.1 \%)$ of the study populations were aware of HIVIAIDS. The proportions of those who have ever heard about the HIVIAIDS were higher in club member $(100 \%)$ than in non-club member $(98.2 \%)$ youths. This finding does go with the research conducted in Jimma and Agaro towns, in which (99.8\%) of the two groups were aware of HIVIAIDS (Meseret, 2003).

From this survey, greater proportions of club member $(96.6 \%)$ and $(92 \%)$ of non-club member respondents were able to mention at least one type of STIS other than HIVIAIDS respectively. Gonorrhoea (79.7\%); syphilis $(75.3 \%)$ and cancroid $(57.5 \%)$ were the commonly stated STIs among club member youths. Among non-club members gonorrhoea (74\%); syphilis $(75.5 \%)$ and cancroid $(61 \%)$ were the usually known STIs. $77.8 \%$ and $88.3 \%$ of the respondents did not know the Lymphogranuloma Venerium from club members and non-members respectively.

Studies conducted in some parts of the country among out-of-school youths revealed that the prevalence of self-reported STIs were (6.5\%), $(4 \%)$ and $(6 \%)$ in Bahirdar, Awassa, and Addis Ababa respectively $(11,19,20)$. In our study selfrepotted signs and symptoms of STIs among sexually active youths were $(4.9 \%)$ among both groups. Half of those who reported history of STIs first consulted peers and a considerable proportion (44\%) got treatment either from local injectors or from private pharmacy, but still they could have been better treated in fair cost in government health institutions.

The FGD discussants said that, youths prefer to go to private clinics, but getting the money to do so from their parents is a problem, especially as they feel they cannot openly discuss their infections. Effectiveness of the treatment and obtaining confidential service were the two main concerns for preferring the visited service areas.

In this survey more than half $(52.5 \%)$ and $(26 \%)$ of club members and non-members
Sci. Technol. Arts Res. J., April-June 2012, 1(2):18-30

reported that they used the contraceptive methods during their last sexual intercourse respectively. The result from this study is with EDHS 2005 report in which (52\%) of unmarried sexually active respondents of the 15-24 age group used contraceptive (Melisew, 2008). However, there is better usage of contraceptive methods among club members than non-club members in the study area, this indicates that most of non-club members involved in high risk sexual practice that endanger their life and their partner life.

Due to low use of contraceptive and condom, adolescents might encounter problems like unwanted pregnancy and abortion, STIs, HIVIAIDS and others.FGD result shows the possible barriers for low utilization of contraceptives may be absence of adolescent friendly services, lack of knowledge, and negative attitude to modern contraception.

This study reports that (52.5\%) and (26\%) among cases and controls respectively. This is much greater and also there was great discrepancy between their knowledge and practice $(95.8 \%$ and $89 \%$ versus. $52.5 \%$ and $26 \%$ ). Selassie also reported similar pattern of discrepancy between knowledge and practice of modern contraceptive use.

The odds ratio points out those non-club members do have bad attitudes and thoughts towards HIVIAIDS victims than club member youths. From this survey, club members are more or less agree with the opinion that a boy/girl should have sex before he/she gets married as non-club members. With regard to AIDS patients' treatment and care, almost all of both groups had affirmative feelings with no statistically significant difference, even if the proportion of club members still outweighs the non-club members.

From FGD result, there are many misconceptions which wide spread among out-ofschool adolescents about HIVIAIDS. The stigma related with HIVIAIDS causes discrimination and this has posed serious obstacles to tackle the epidemic. Stigma and discrimination are a result of ignorance about the disease was traditional and religious attachment about sex, sexuality and STIs.

Almost three fourth $(72.5 \%)$ of club members perceived that they are at risk or may be at risk of acquiring the disease than the non-club members $(54.7 \%)$. This figure was greater than a study conducted in Jimma and Agaro towns that twothirds of the club members admitted that they are 


\section{Elias Legesse Negeri}

at risk or might be at risk of acquiring HIV and two-third of the non-club members reported that they are at risk (Meseret, 2003). In this study club member youths perceived that they are at risk of acquiring HIVIAIDS than the non-club members.

In this survey the figures in risk perception were relatively higher when compared with other studies. Our finding was even more encouraging compared to findings of south Gondar in which $(5.8 \%)$ of the respondents perceived to have a high chance of acquiring HIV (Lema and Hassen, 1994). In South Africa (30\%) of respondents perceive that they are at risk of HIV. This can have a positive influence on reducing high-risk behaviors, thus, reduces a major risk factor of HIV acquisition (Adugna, 2005).

In the present study it was tried to assess the most frequently mentioned reason, by those who did not perceive themselves as at risk, $(27.5 \%)$ was that they did not have any sexual contact; $(13.2 \%)$ was that they regularly use condom; followed by because of praying regularly, $(20.8 \%)$. The proportions that perceive themselves as at risk of contracting HIV are highest among females (69.1\%) than males (30.9\%).

In this survey a number of factors including total number of reported sexual partners, knowledge on HIV transmission, willingness to get tested (VCT), condom use during first sexual intercourse and alcohol intake have shown significant association with self-risk perception. Similar finding was obtained from Debre Birhan town on HIV risk perception was found to be associated with condom use, knowledge on HIV transmission, number of sexual partners and khat chewing (Abdu Dawud, 2003).

Generally, this study revealed that knowledge, perception and attitude of the club members are better off. This is probably the result of repetitive and multiple information sources they had compared to the non-club members. Because of increased knowledge and heightened practices lead youths to recognize that new behaviors can meet a personal need, to decide to take action and eventually to adopt new practices (Hibret, 2004).

In this survey, $61.5 \%$ of the students heard about voluntary counseling and testing for HIV. Five point nine percent $(5.9 \%)$ reported history of previous VCT, and $(82.2 \%)$ agreed to undergo voluntary counseling and testing for HIV.
Sci. Technol. Arts Res. J., April-June 2012, 1(2):18-30

In FGD also, most of the youths know that taking VCT has multi-advantages, but a very small proportion of the people used this service. Among those who took the service the majority took pre-marriage VCT, but pre-sexual VCT is very minimal.

Study groups, sex of respondents and number of lifetime sexual partners were significantly associated with willingness to VCT. Those who reported single sexual partner were almost more willing to undergo VCT (AOR=1.89(1.22, 3.32)) than those who reported to have two or more sexual partner. Males were almost more willing to undergo VCT (AOR=2.84(1.58, 5.52)) than females, and similarly in the present study, the club members are more likely to show an attention for voluntary HIV testing and counselling, whereas club members were more voluntary to disclose or reveal the test result to others $(A O R=1.87(1.53,3.25)$ than the non-club member respondents.

Similarly in the present study, knowledge of HIV status is found to be a strong predictor variable to influence the level of risk perception of HIV infection among the respondents. Those respondents who had never been tested for HIV are 2.56 times more likely to perceive higher risk of HIV infection than respondents who took VCT. The result of this study was analogous with the study conducted in Dessie town in which the respondents who had never been tested for HIV were 2.779 times more likely perceive higher risks for HIV.

\section{CONCLUSIONS}

The majority of the respondents in the present study perceived themselves as being at little or no risk of HIV infection. Their reported sexual behavior indicate that a significant proportion of the respondents involve in risky sexual activities that could expose them to HIV infection. They had unfavorable attitude towards HIVIAIDS patients manifested, and the perception of risk acquisition is weak. A considerable number of out-of-school youths reported that they have involved in non-sexual risk behaviour such as chewing khat, drinking alcohol and watching pornographic films which are found to play significant role in predisposing the youths to risky sexual practices.

Though, parent youth discussion about sexual matters have found to be significantly associated with out-of-school youths sexual experience, they didn't discuss openly the information on issues of sexuality to their children, but there is open 


\section{Elias Legesse Negeri}

discussion with their peers about sexuality, condom use and other related issues. Peer pressure was also found to be another driving force that predispose youth for risky sexual practices.

Even in the face of existing perception and knowledge of self-risk, risk taking behaviors (first sex at early age, multiple sexual partnership, sex with high risk partners such as CSW, non-use of condom for every act of sexual intercourse, low HIV test service uptake, etc.) is still high.

\section{ACKNOWLEDGEMENTS}

I would like to offer my deepest appreciation and thanks to Dr. Alemayehu Worku for his constructive advice, support, valuable comments and suggestions. I would like to acknowledge the help provided by the staff of llu-Abba-Bora Zone Health Bureau, Mettu and Bedelle woreda Health Bureau and Bedelle town Capacity Building Bureau for their full cooperation and facilitation of the actual data collection procedure. I would also like to sincerely thank to supervisors and to all the participants of the study for their participation.

\section{REFERENCES}

Abate, S. (2001). Determinants of High Risk Sexual Behavior for HIVIAIDS among Out-of-School Youth in Addis Ababa. MPH master thesis, Addis Ababa University.

Abdu Dawud. (2003). Perception of the Risks of Sexual Activities among Out-of-School Adolescents in South Gondar Zone, Amhara Region, Addis Ababa University.

Adugna, B. (2005). The Relationship between Adolescents Perception of Parental Monitoring Connectedness and Communication and their Sexual Risk Taking Behavior. The Case of Nekemte High School. MA Thesis, Addis Ababa University.

Ahimbisibwe, E. (1998). Risk Perception and Condom Use in Uganda. African Population Studies 18 (1): 68-80.

Degaga, W. (2007). Assessment of the Causes and Problems of Commercial Sex Workers: The Case of Adama City, Oromia Regional State. MA thesis, Institute of Gender Studies, Addis Ababa University.

Eggleston, E. (2000) Consistency of Self-Reports of Sexual Activity Adolescents in Jamaica. International Family Planning Perspective 26(2): 79-83.

Fantahun, M., Chala, F. (1996). Sexual Behavior and Knowledge and Attitude towards HIVIAIDS among Out-of -School in Bahir Dar town. Ethiopian Medical Journal 34: 233-242.
Sci. Technol. Arts Res. J., April-June 2012, 1(2):18-30

Hibret, A., (2004). Factors Predisposing Out-of-School Youth to High Risk Sexual Practice with Respect to HIV Infection in Bahir Dar town, Northwest Ethiopia. MPH thesis, Addis Ababa University.

International Labor Office. (2004). HIVIAIDS and Work: Global Estimates Impact and Response.

Kidanu, A. (2002). Youth Reproductive Health in Ethiopia. MIZ-Hassab. Research Center.

Lema, V.M., Hassen, M. (1994). Knowledge of Sexually Transmitted Diseases, HIV Infection and AIDS among Active Adolescents in Nairobi, Kenya and its Relationship to their Sexual Behavior and Contraception. East African Medical Journal 71(2): 122-128.

Melisew, M. (2008). Premarital Sexual Practice and Perception of High Risk of HIVIAIDS among School Adolescents in Injibaratown, Awi zone. MPH Thesis, Addis Ababa University.

Meseret, Y. (2003). Assessment of HIVIAIDS Risk Behavior Difference between Out-of-School AntiAIDS Club Member and Non-Club Member Youths, Jimma and Agarotowns, South West Ethiopia, Addis Ababa University.

Silieshi, T. (2005). Determinants of Risk Sexual Behavior in Bahir Dar among Adolescent, M.Sc Thesis in Demography, Addis Ababa University.

UNAIDS (2008). Preventing HIVIAIDS in Young People A Systematic Review of the Evidence Global HIVIAIDS Epidemic.

UNICEF, UNAIDS and WHO (2002). Young people and HIVIAIDS. Opportunity in crisis. Geneva: WHO.

Wosen, Y. (2005). Adolescents' Perception on Sexual Health Issues: A Case High School Student in Addis Ababa, M.Sc Thesis, Addis Ababa University.

Youth Net. (2004). Assessment of Youth Reproductive Health Programs in Ethiopia. Addis Ababa. 